\title{
Nanotechnology: Concepts, Importance and the Current State of Scientific Research
}

\author{
Samieh Abu Saad ${ }^{1 *}$, Amani Elmahjubi ${ }^{2}$ \\ ${ }^{1}$ Head of Engineering Department, Industrial Research Centre Tajoura, Libya \\ ${ }^{2}$ Head of Chemicals\& Glassware Storage Unit, Industrial Research Centre Tajoura, Libya \\ DOI: https://doi.org/10.21467/proceedings.4.22 \\ * Corresponding author email: samieh7@yahoo.com
}

\begin{abstract}
In nowadays, research in nanoscale science has been greatly developing and obtaining more interests. Numerous research activities in the last two decades focus on exploring nanoscience, understanding the fundamentals, and developing technical solutions. Materials in nanoscale showed remarkable and superb properties that are completely different from those when the material in the bulk condition. This makes nanotechnology to hold a great promise in effecting profound scientific, medical, energy, economic and even cultural change on society. Almost all countries are placed long and short term strategic plans as to obtain more experience and carefully examine the potential implications of nanotechnology and its strategic benefits. Consequently, research indicators on this technology indicate that some developing countries compete with the world's largest countries in the control of this technology. This paper, however, provides an introduction to the nanotechnology, and also discovers the current status of the research on this particular field globally and in the Arabic region. The real status of the scientific research on the nanotechnology in Libya correspondingly is realised. Steps required by the Libyan authorities and research principles to fill in the gape in this area are also expressed.
\end{abstract}

Keywords: Nanotechnology; Nanoscience; Research in Nanotechnology; Nanotechnology Applications.

\section{Introduction}

Nanotechnology has become a competitive scientific technology that most of developed countries competed to control. The research and development in this particular field of technology has impacted every aspect of modern human life. More and divers areas of research have been continuously increasing and gaining the interest of researchers and scientists to apply this kind of technology and benefit from [1]; e.g. energy; agriculture; petroleum industry; food industry; and probably the strongest field is medicine and healthcare. Nanotechnology refers to the science and technology of which a matter is controlled in a nanoscale. It is commonly attributed for the technologies leading to produce nanoscale materials at nanometre dimension (10-9 m) [2,3]. The nanoscale is consensually considered to cover the range of 1

(C) 2018 Copyright held by the author(s). Published by AIJR Publisher in Proceedings of First Conference for Engineering

Sciences and Technology (CEST-2018), September 25-27, 2018, vol. 2.
This is an open access article under Creative Commons Attribution-NonCommercial 4.0 International (CC BY-NC 4.0)

A iR license, which permits any non-commercial use, distribution, adaptation, and reproduction in any medium, as long as the original work is properly cited. ISBN: 978-81-936820-6-7 
Nanotechnology: Concepts, Importance and the Current State of Scientific Research

to $100 \mathrm{~nm}$. According to the US National Nontechnology Initiative (NNI), the nanotechnology is 'the understanding and control of matter at dimensions between approximately 1 and 100 nanometres, where unique phenomena enable novel applications. Encompassing nanoscale science, engineering, and technology, nanotechnology involves imaging, measuring, modelling, and manipulating matter at this length scale'. Yet, numerous definitions of nanotechnology have migrated and expanded with the passage of time. For instance, in [4], the definition is expressed as 'nanotechnology is the design, characterization, production and application of materials, devices and systems by controlling shape and size of the nanoscale'. While in [5], a slightly different nuance is given by 'the deliberate manipulation, precision placement, measurement, modelling and production of matter at the nanoscale in order to create materials, devices and systems with fundamentally new properties and functions'. Another different definition, though floating around, is introduced in [6] that is 'the design, synthesis, characterization and application of materials, devices and systems that have functional organization at least one dimension on the nanometre scale. Obviously, the definitions, however, should provide some form of proactive engineering to the term nanotechnology. Nevertheless, to avoid the debate about the definition as it is not the particular scope of this paper, it would be better to suggest that a certain technology can be considered nanotechnology only if it involves all of the following three attributes: first, research and technology development at the atomic, molecular or macromolecular levels, in the scale of approximately 1-100 $\mathrm{nm}$ range; second, creation and use of structures, devices and systems that have novel properties and functions because of their small and/or intermediate size; and finally, an ability to control or manipulate on the atomic or the nanoscale [7].

This paper provides an introduction to the basic principles and applications of nanotechnology. It also discovers the current status of research on this particular field globally and in Arabic countries. The real situation of the scientific research on nanotechnology in Libya is finally concluded, and steps required by authorities and research principles to motivate the research in this area are expressed.

\section{Importance of Nanotechnology}

Nanotechnology is considered as a powerful tool and technique in medical technology as well as almost every filed life. This kind of technology develops so fast; while its applications diverse to touch all branches of science, engineering and industries. The momentum of nanostructures stems from the fact that new materials with absolutely new properties can be developed. Properties of a matter depend strongly on how atoms are arranged in space; e.g. if atoms in coal (Carbon) is rearranged, it could make diamond. Therefore, nanotechnology holds great opportunities for innovation in, virtually, every industry and application. New materials and advanced devices of a desirable properties and functions can be developed for numerous applications using this technology. The main aspects that make nanotechnology attractive to researchers are the fact that it is relatively cheap, can be manufactured in bulk with lower energy; the ability to control the material's properties by controlling its particles 
size and structural form as well as controlling the conditions and methods of preparation; and relatively safe in terms of use for people and environment [8]

\section{Influence of Size on the Materials' Properties}

Owing to the small size of the building blocks (particle, grain, or phase) nanomaterials demonstrate unique mechanical, optical, electronical, and magnetic properties [3]. Properties of nanomaterials depend on [9]: fine grain size and size distribution $(<100 \mathrm{~nm})$; the chemical composition of the constituent phases; the presence of interfaces, more specifically, grain boundaries, hetero-phase interfaces, or the free surface; and lastly interactions between the constituent domains.

Changes in the size-dependent properties of a matter are observed due to the fact that wavelike properties of electrons inside the matter and atomic interactions are influenced by the size of materials at the nanometre scale. Confinement of the DeBroglie wavelength of charge carriers inside nanomaterials could also lead to quantization effect [3]. As the size decreases, the ratio of atoms on the surface increases. Such atoms are high energy surface atoms and very reactive. This also creates a high surface to volume ratio leading to a tremendous improvement in chemical properties. Platinum nanoparticles, for example, are efficient catalysts for many reactions whereas platinum bulk sheets are sufficiently inert $[8,9]$. Large surface to volume ratio means subtle changes to the surface due to addition of numerous atoms or molecules leading to dramatic alterations of physical properties. Number of fields, including magnetism, luminescence and renewable/alternative energy to sensors as well as photo-catalysis, will benefit from capitalizing on the surface-volume relationship. The possible enhancement of physical properties is therefore due to quantum size and clustering interface effects [10]. Figure 1 shows how surface volume ratio changes with particle size.
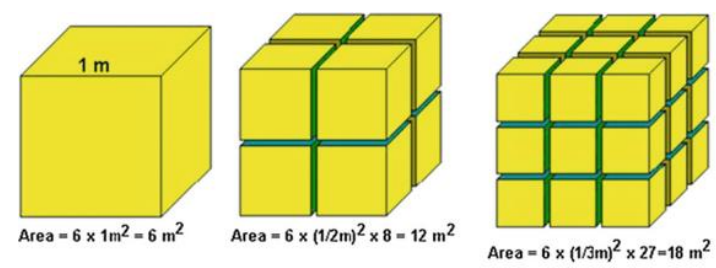

Figure 1: The surface volume ratio changes with particle size.

\section{Nanofacture}

There is a wide variety of technologies that have the potential to produce nanomaterials with different degrees of quality, speed and cost. Yet, grain size, shape and structure of the required nanomaterials are the main factors restrict the selection of the technology [11]. Almost all of these techniques fall into the main categories described in Figure 2. The top-down methods mostly require large (and also expensive, needs considerable concentrations of capital) installations [11]. Traditionally, scaling-down processes are based on process that include

Proceedings of First Conference for Engineering Sciences and Technology (CEST-2018), vol. 2 
Nanotechnology: Concepts, Importance and the Current State of Scientific Research

grinding or etching and utilise an ultraprecision engineering. Mechanical stiff parts are used to ultra-precisely shape objects. While on the other hand, for semiconductor processing a very high-quality thin films are deposited, either physical vapour deposition (PVD) or chemical vapour deposition (CVD), with nanometre control, perpendicular to the plane of a substratum $[11,12]$. Sophisticated technologies, e.g. exposure to a plasma, or ions implantation, are employed to modify existing surfaces of materials [12].

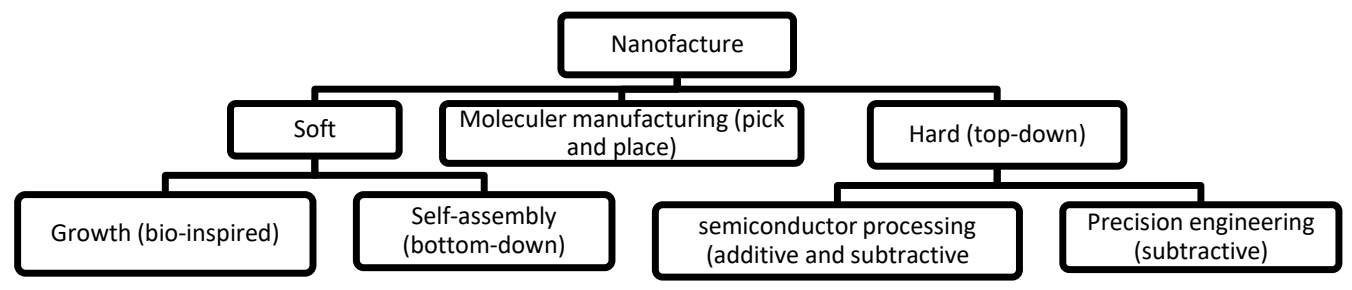

Figure 2: Different modes of nano-manufacture (nanofacture).

The other approach is known as molecular manufacturing; also known as "pick and place" or bottom-to-bottom methods, literally construct things atom-by-atom [11, 12].

The third approaches, known as bottom-up or self-assembly, are based on creating objects that capable of spontaneously assembling into useful structures. Precursors are gathered in random positions and orientations, and supply energy to allow them to sample configuration space. Once the precursors are in position, the bonds connecting them are strengthened and the final object is fixed permanently $[11,12]$.

\section{The Current Situation of Research in Nanotechnology}

To study the development trends of the research in nanotechnology, the outcomes of nanotechnology related research is examined. Indicators; namely, funding, publications and patents are presented, investigated and analysed. The results of such studies would also help policy makers in assessing their past policies, forecasting future trends based on the previous and contemporary trends [14], and take new valuable actions to succeed.

\subsection{Globally}

Governmental funding plays a critical role in establishing and stimulating nanotechnology research and development $(\mathrm{R} \& \mathrm{D})$. Based on the Global Funding of Nanotechnologies \& its Impact report [15], since 1997 the United States (US), followed by most countries in the European Union (EU), and other countries have announced series of policies and heavy funding to support academia for the field of nano-innovation R\&D. Since then, as denoted in Figure 3, this budged was gradually increasing. Remarkably, the US outspends every country else. Yet Japan and Russia have managed to take a temporary lead in 2000-2003 before fall back. Also, it points out that the funding trend in EU grows gradually; while on the other hand faster growth rates are observed in Asia. 


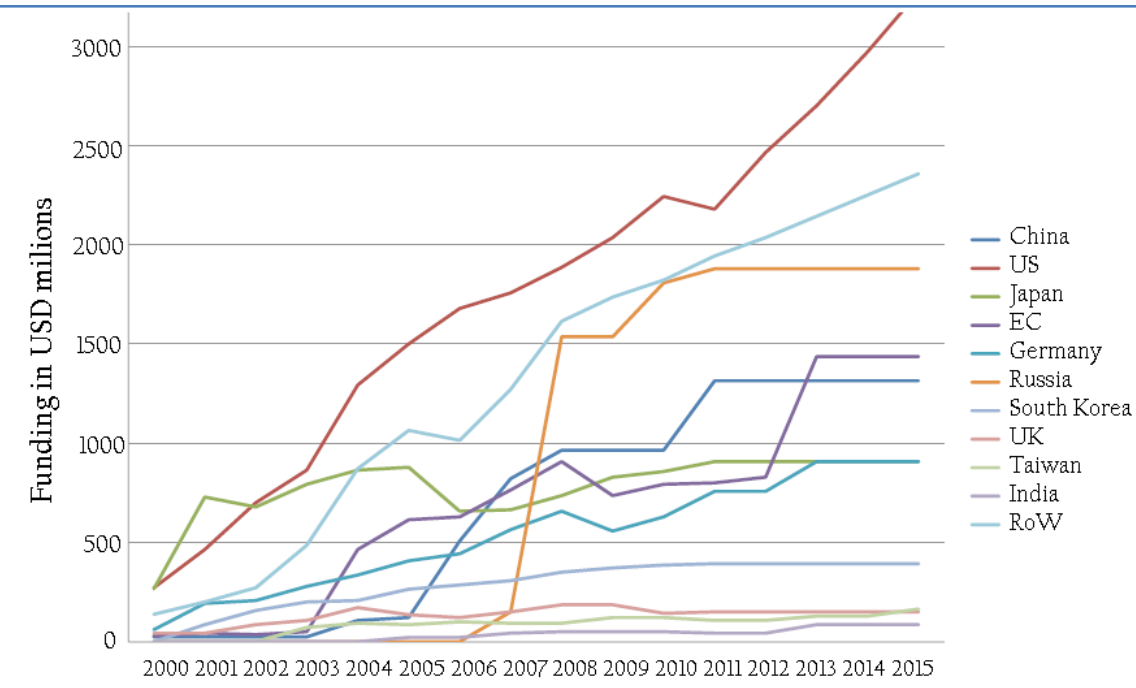

Figure 3: Funding of nanotechnologies by country [15]

Such funding is expected to positively reflect on the nanotechnology related R\&D activities. This can be observed in the number of nanotechnology related articles and the number of granted patents annually. These two figures are mainly considered when examining the outcomes of R\&D activities [14]. Visibly, scientific articles are the major source of knowledge production and transfer from academic research to industrial applications and developing innovations [14].

In this work, statistics of published scientific articles are obtained from the Thomson Reuters Web of Science (WoS) which are usually used for retrieving and analyzing academic research outputs [15]. Additionally, to avoid confusion and for better understanding only the top 5 countries are considered for the period of 2010-2017 as represented in Figure 4. It reveals that China possesses the highest rate of growth with about $47 \%$ while the US comes second with mostly half growth rate. Remarkably, India, South Korea and Iran rank in the list with growth rate of about $24 \%$.

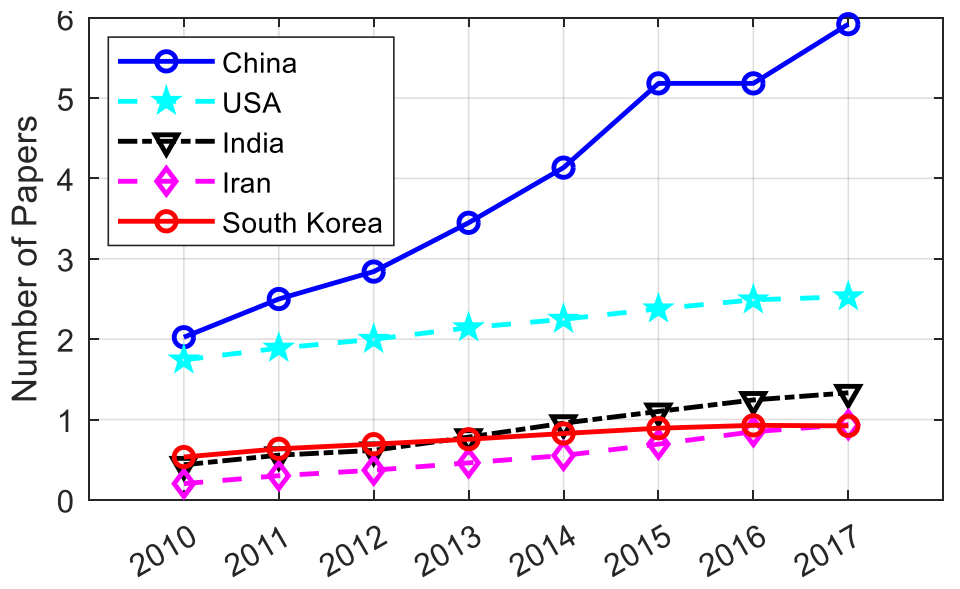

Figure 4: The number of nanotechnology article in 2010-2017

Proceedings of First Conference for Engineering Sciences and Technology (CEST-2018), vol. 2 
Nanotechnology: Concepts, Importance and the Current State of Scientific Research

Nevertheless, number of articles need to be carefully analysed when used as an indicator for nanotechnology developing. Obviously, it is related to other figures such as population, stage of development, percentage of R\&D expenditures, and some other important factors. Therefore, to reliably analyse data, another index is deployed to study the growth of nanotechnology research globally; i.e. the local share of nano-articles to total articles published by each country. Figure 5 shows the top 5 shares (\%) in 2010-2017. It represents that Asian countries have the highest share in this indicator, and almost all of them have shares higher than the world average (9.5\%). Iran and Saudi Arabia have consist increasing share and achieved their highest shares in 2017. Both have experienced huge growth in the published nano-articles by giving propriety to nanotechnology research. Noticeably, Bahrain is in this particular list indicating the level of interest paid to this technology.

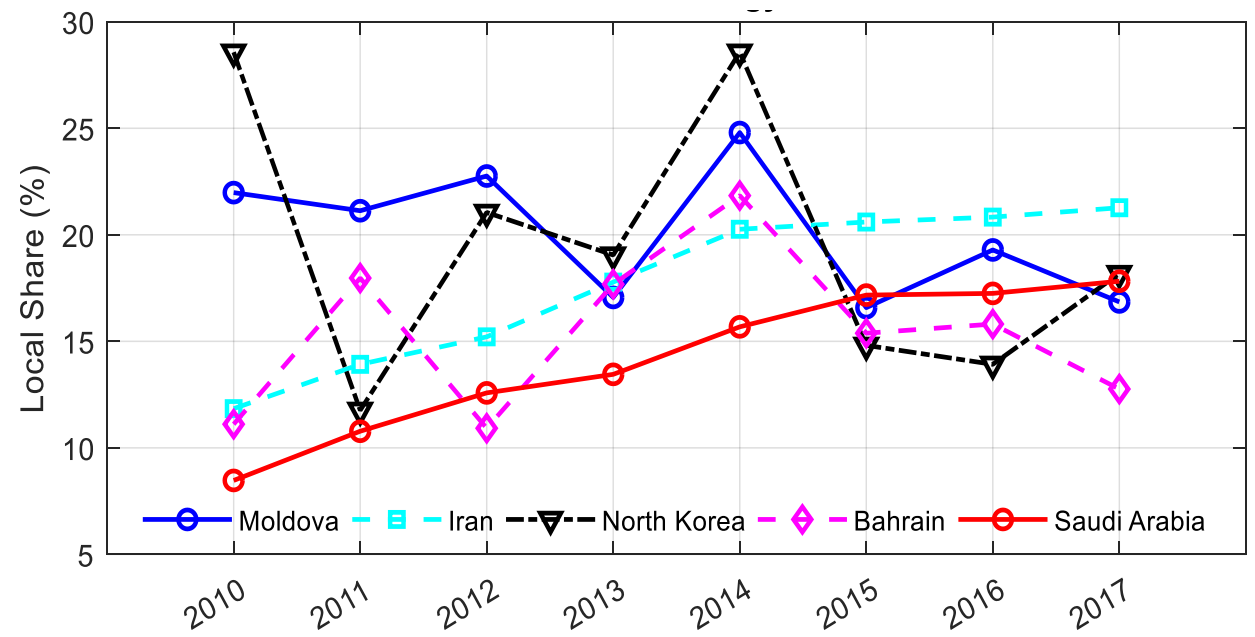

Figure 5: The local share in nanotechnology articles in 2010-2017

It is worth mentioning that although US is ranked $2^{\text {nd }}$ in published nano-articles, it possesses an average share of around $6 \%$ in 2010-2017. While India ranked $6^{\text {th }}$ in this list explaining the reason they both are not appearing in Figure 5. To further analyse the global development in nanotechnology, patents number is employed as a technology and innovation indicator. Patent data were retrieved from the United States Patent and Trademarks Office (USPTO) and European Patent Organisation (EPO). Figure 6 represents the nanotechnology patents granted in the USPTO in 2010-2017. It shows that US ranks $1^{\text {st }}$ by possessing $60 \%$ of all nanotechnology patents. Noticeably, South Korea has consistent increasing patents and ranked $2^{\text {nd }}$ in 2017 moving Japan $3^{\text {rd }}$ with a gap of 500 patents. 
Saad et al., CEST-2018, AIJR Proceedings 4, pp.552-562, 2018

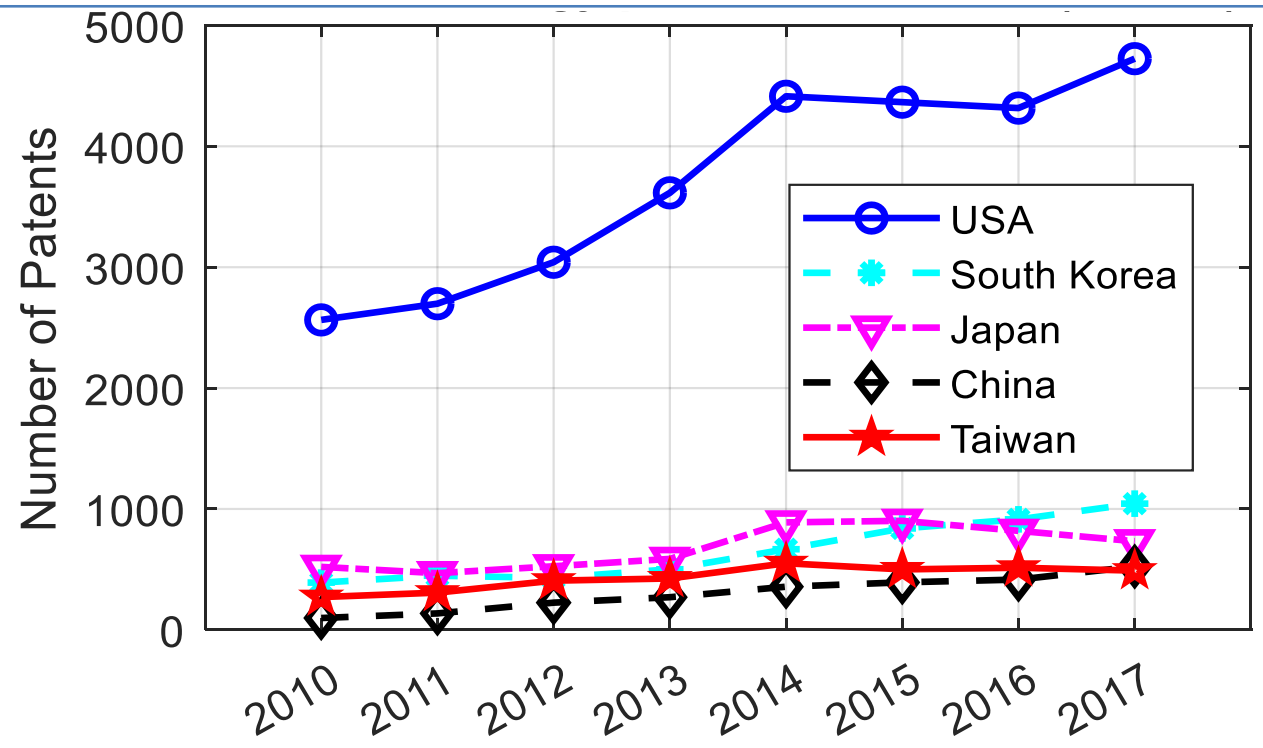

Figure 6: Nanotechnology related patents in USPTO

The EPO also shows that US possesses the highest patents granted in 2010-2017 as denoted in Figure 7. Apart from France and Japan, the gap between each country and other is visible.

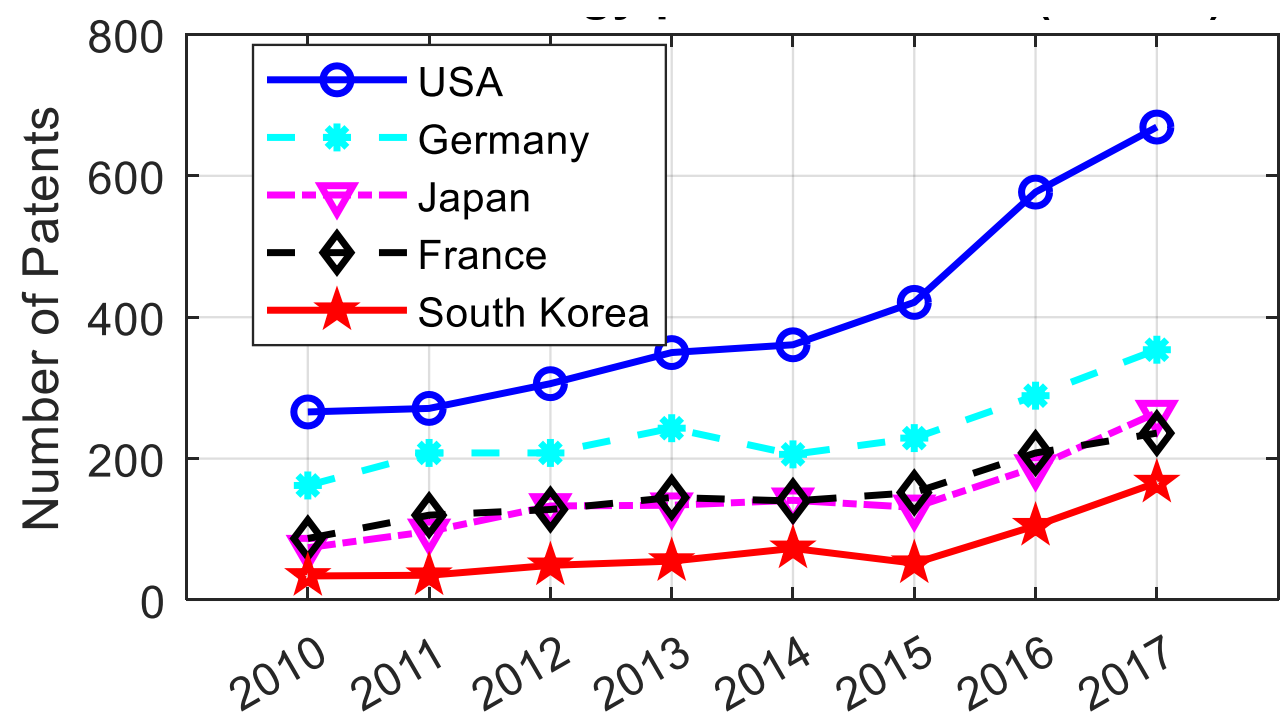

Figure7: Nanotechnology related patents in EPO

\subsection{The Arabic countries}

Similarly, the current situation of research in the field of nanotechnology in Arabic countries is explored using both the number of publications and corresponding local share. It is worth mentioning that trusted resources about the exact funding spend on nanotechnology related R\&D by most Arabic governments is not available. Hence only publications number and local 
Nanotechnology: Concepts, Importance and the Current State of Scientific Research

share are explored. Additionally, due to the fact that published articles are very small in contrast to that published globally, the accumulative number in 2000-2017 is used instead, as denoted in Figure 8. Saudi Arabia has the highest accumulative number with more than 8000 articles, followed by Egypt with about 7750 articles. The rest are all either around 1500 articles or reasonably lower; whereas Libya stands in the back with less than 100 articles.

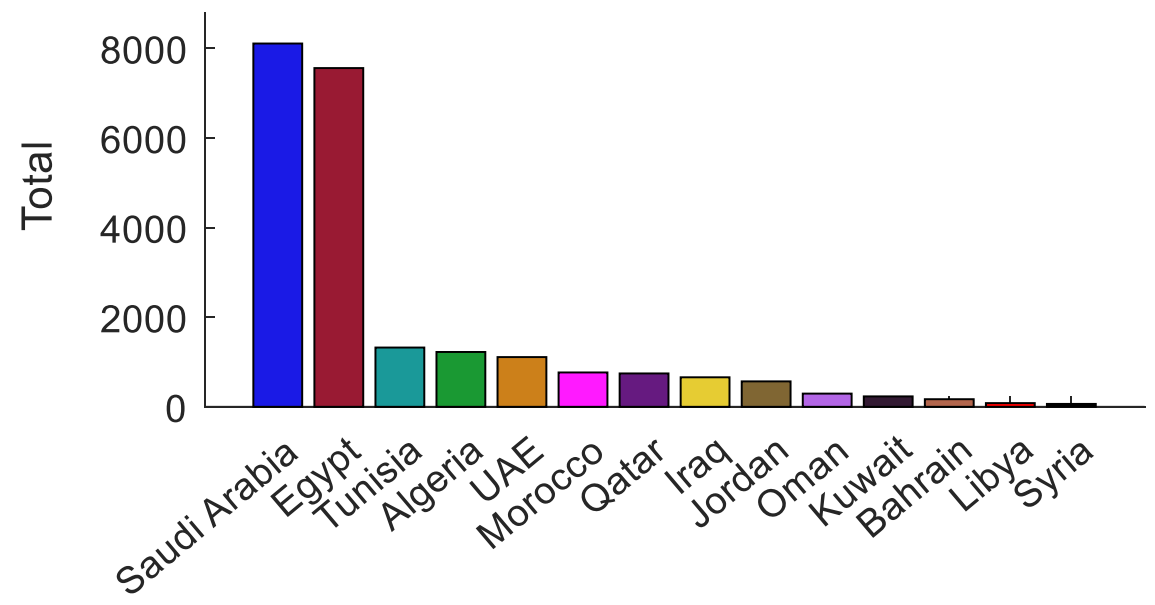

Figure 8: Published nanoarticles in Arabic countries, total in 2000-2017

The local share is also calculated for every single Arabic country and represented in Figure 9. It appears that Saudi Arabia leads the list with about $8 \%$ share; Qatar comes $2^{\text {nd }}$ with $6 \%$. UAE, Iraq, Bahrain, Kuwait and Egypt have close shares of about 5\%. Libya has no share calculated as a trusted total number of articles is not available.

More, apart from Saudi Arabia patents granted in USTPO by Arabic countries is as small as less than 8, see Figure 10. In fact Saudi Arabia has been ranked $12^{\text {th }}$ globally in USPTO.

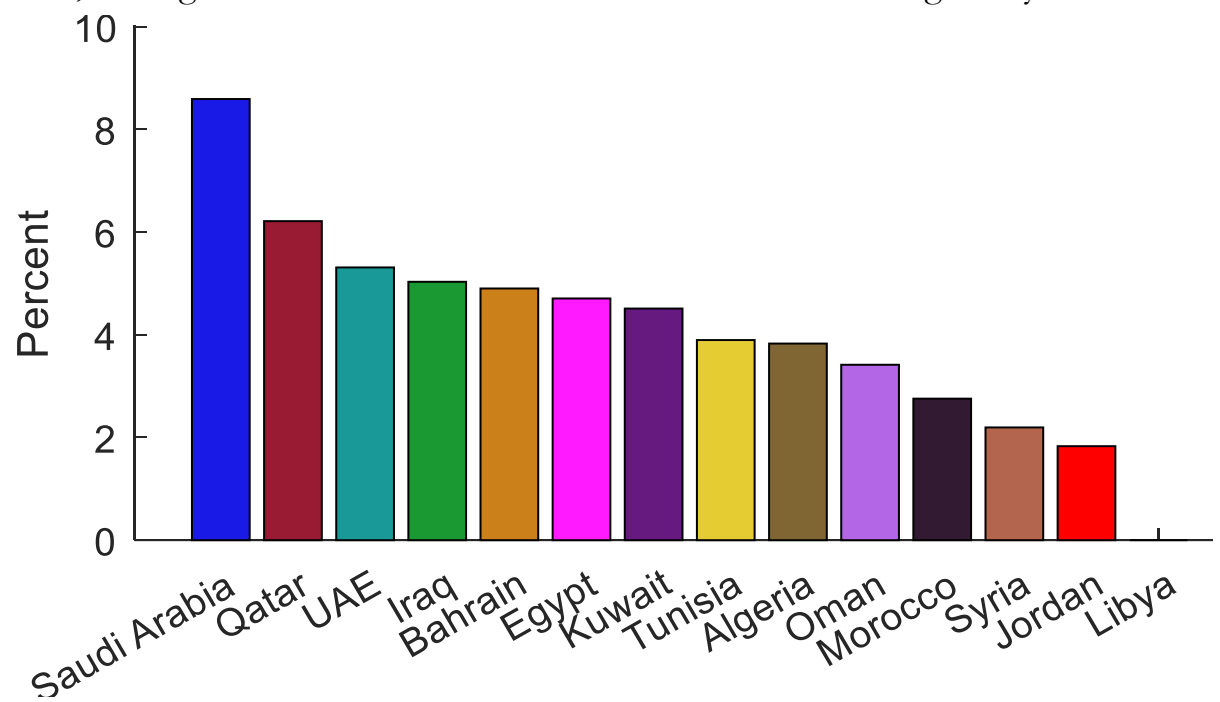

Figure 9: Local share of nanoarticles in the Arabic countries 
Statistics from EPO showed similar results to that of the USPTO indicating that research activities in nanotechnology is still in early stages in Arabic countries. However; Saudi Arabia represents the best performance and possesses advanced position globally.

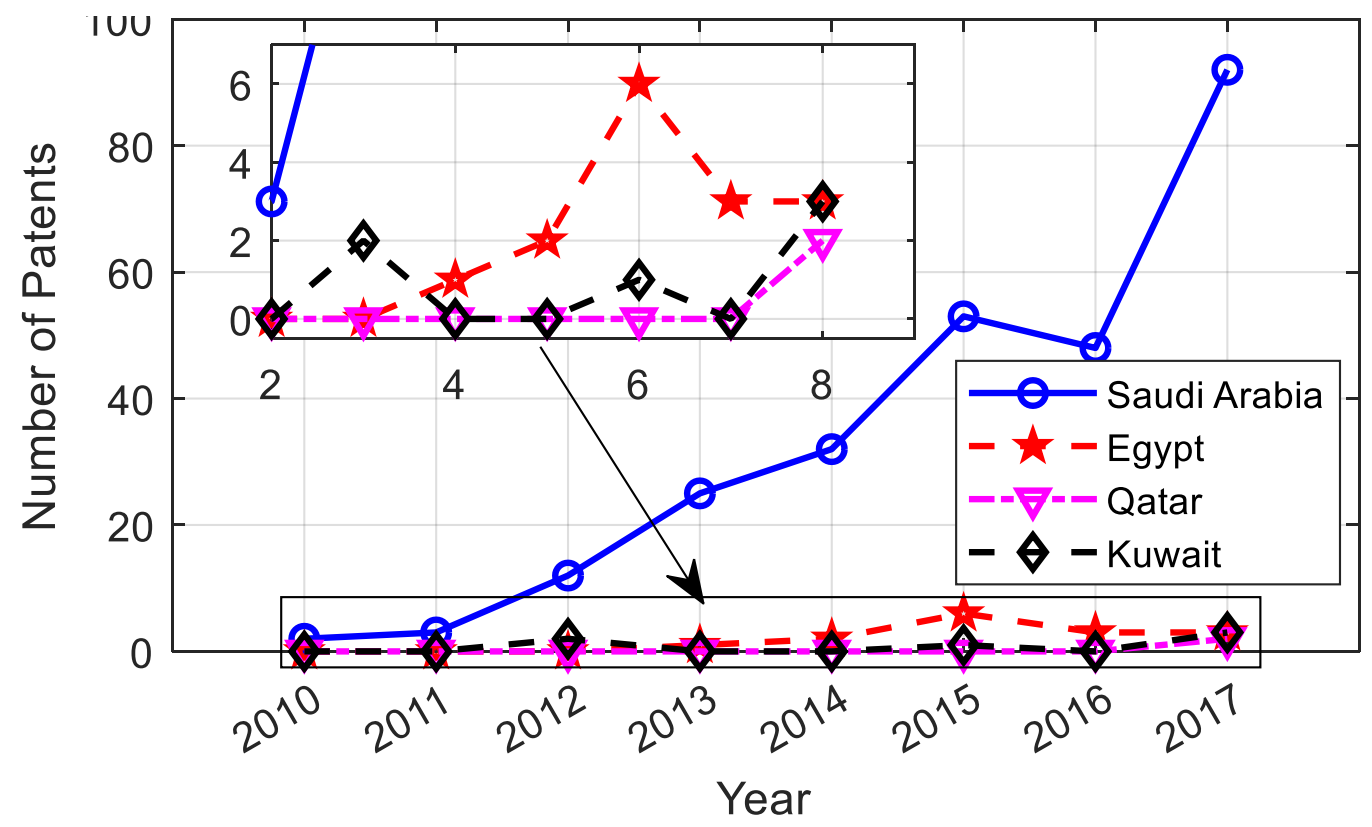

Figure 10: Arabic nanotechnology related patents in USPTO

To further analyse the current situation in Arabic countries, the Global Innovation Index (GII) [16] in 2013-2017 is discovered. This would also provide detailed metrics about the innovation performance in Arabic countries. Table 1 represents the ranking of GII of top 10 Arabic countries. It illustrates that UAE ranks first mostly in 2013-2017. Particularly it possesses the $35^{\text {th }}$ globally in 2017. Qatar also showed good performance in that it moved from the $50^{\text {th }}$ globally in 2016 to 49 th Saudi Arabia also develops gradually, although its rank decayed from 49th in 2016 to $5^{\text {th }}$ in 2017 globally moving to $3^{\text {td }}$ in the Arabic GII list. Kuwait, Bahrain and Morocco have systematic improvement in the GII globally. The table indicates that the some Arabic countries keen interest in innovation. In fact, innovation is the main pillars for a highproductivity knowledge economy. It is worth mentioning that these countries have made important progress by localization of nanotechnology research in universities and research bodies as well as establishing specialized research centres in the field of nanotechnology. For instance, Saudi Arabia established 6 institutes specialised in nanotechnology and at least three companies in the field of Nanotechnology industries; while almost all universities have departments educate nanoscience and nanotechnology. Egypt also possesses the highest number of specialized organizations, institutions and research centres in Arabic countries; i.e. more than 10 [17].

Proceedings of First Conference for Engineering Sciences and Technology (CEST-2018), vol. 2 
Nanotechnology: Concepts, Importance and the Current State of Scientific Research

Table 1: Global rankings of Arabic contries in GII.

\begin{tabular}{|c|c|c|c|c|c|}
\hline \multirow{2}{*}{ Country } & \multicolumn{5}{|c|}{ Arabic countries GII ranking } \\
\cline { 2 - 6 } & 2013 & 2014 & 2015 & 2016 & 2017 \\
\hline UAE & 38 & 36 & 47 & 41 & 35 \\
\hline Qatar & 43 & 47 & 50 & 50 & 49 \\
\hline Saudi Arabia & 42 & 38 & 43 & 49 & 55 \\
\hline Kuwait & 50 & 69 & 77 & 67 & 56 \\
\hline Bahrain & 67 & 62 & 59 & 57 & 66 \\
\hline Morocco & 92 & 84 & 78 & 72 & 72 \\
\hline Tunisia & 70 & 78 & 76 & 77 & 74 \\
\hline Oman & 80 & 75 & 69 & 73 & 77 \\
\hline Lebanon & 75 & 77 & 74 & 70 & 81 \\
\hline Jordan & 61 & 64 & 75 & 82 & 83 \\
\hline
\end{tabular}

\section{Development of Nanotechnology in Libya}

Pessimistically, the concern for this technology in Libya, formally, is not yet clear. Despite the attempts from scholars, research centres and universities to concretize it; yet these efforts are solitary and not comprehensive. Figure 8 showed that only around 85 articles were published globally. Governmental actions are urged to initiate programs that involve different institutions, focuses on the $\mathrm{R} \& \mathrm{D}$, the creation of human capacity, the provision of infrastructure. Steps need to be taken may include but not limited to:

- Establish clear and objective policies as well as national initiative with obvious objectives and visions for excellence in this particular field to create a favorable investment environment;

- Establish and implement an objective plan for scientific and technological research and innovation in the field of nanoscience and technology. The plan should include the foundations of joint cooperation to maximize the benefit from the scientific and human resources available in R\&D centres, institutes and universities;

- Provide the necessary long term resources for the constitution of capacities; and suitable funds toward R\&D to motivate the development in this field;

- Encourage (i.e. by funds, special policies and targeted intermediaries) to involve scientists, researchers, and scholars in the nanotechnology field, and establish clusters or networks to adapt and develop rapidly;

- Promote management in mediators to focus on linking academic and industrial organisations together, in order to motivate collaborative research and innovation;

\section{Conclusions}

This work has provided a brief introduction to the nanotechnology, including definition, the basic principles, applications, and manufacturing methods. It is also expanded to identify the 
global pattern of nanotechnology related indicators, i.e. articles number, patents number and GII, in a developmental context in 2010-2017. Based on the analysis, the results reveal that the most of developed countries have made a considerable funding to support and encourage academia for the R\&D in the field of nanotechnology. The USA and china have the highest indicators; while countries in Asia, generally, have showed the fastest growing rate. The study also showed that some Arabic countries have dramatically improved nanotechnology indicators. Namely, Saudi Arabia has identified increasing trend and systematic development in most indicators studied. Qatar, UAE, Kuwait, Bahrain and Egypt have also experienced developing trends. On the other hand Libya stands back in almost all indicators. Libyan policy makers must take serious actions to initiate strategies, make funds available and initiative programs that involve institutions focus on $R \& D$, creation of human capacity, and the provision of infrastructure to encourage scientists and researchers to develop their related nano-activities.

\section{References}

[2] Carolina Fracalossi Rediguieri, "Study on the development of nanotechnology in advanced countries and in Brazil," Brazilian Journal of Pharmaceutical Sciences vol. 45, n. 2, abr.jun. 2009

[3] Kannaparthy R., Kanaparthy A. "The changing face of dentistry: nanotechnology”. Int J Nanomedicine 6: 2799-804. 2011

[4] Iadiz MAR, Bamedi M, Fakour SR "Periodontal Diseases and Recently Applied Nano-Technology: A Review Article." Health 9: 345-51. 2017

[5] E. Abad et al "Nano Dictionary. Basel: Collegium Basilea" 119-146, 2005

[6] Jeremy Ramsden "Essentials of Nanotechnology”.Ventus Publishing ApS, SBN-13: 9788776814182, 2009

[7] Lubick N; Betts ‘Kellyn "Silver socks have cloudy lining” Environ Sci Technol. 42 (11): 3910, 2008.

[8] RocoMC "Building foundational knowledge and infrastructure for nanotechnology: 2000-2030". Chapter 4. In: Cheng et al (eds) 'anotechnology: delivering the promise', vol 1. ACS, Washington, DC, pp 39-52, 2016

[9] Liming Dai (Ed.) "Carbon Nanotechnology: Recent Developments in Chemistry, Physics, Materials Science and Device Applications”, Elsevier: Amsterdam, 2006.

[10] Hari Singh Nalwa, "Nanostructured Materials and Nanotechnology", Elsevier, ISBN: 0080537278, 2001

[11] Günter Schmid "Nanotechnology. Volume 1: Principles and Fundamentals" WILEY-VCH Verlag GmbH \& Co. KGaA, WeinheimISBN: 978-3-527-31732-5. 2008

[12] Jeremy R. Ramsden, ”Applied Nanotechnology”, Elsevier Inc, ISBN: 978-0-8155-2023-8, 2009

[13] Jeremy R. Ramsden, ”Nanotechnology: An Introduction”, Elsevier Inc, ISBN: 978-0-08-096447-8, 2011

[14] Wang J, Shapira P "Funding acknowledgement analysis:an enhanced tool to investigate research sponsorshipimpacts: the case of nanotechnology". Scientometrics87(3):563-586, 2011

[15] Gorjiara T, Baldock C "Nanoscience and nanotechnologyresearch publications: a comparison between Australia andthe rest of the world". Scientometrics 100(1):121-148, 2014

[16] http://cientifica.com/wp-content/uploads/downloads/2011/07/Global-Nanotechnology-Funding-Report-2011.pdf; accessed on 14/06/2018 @ 12:01PM

[17] https://www.globalinnovationindex.org/

[18] ALECSO "A diagnostic study to survey the possibilities in the field of nanoscience and technology in the Arabic world", A study launched by the Arab Organization for Industrial Development and Mining, 2017. 